Original scientific paper

\title{
SIMULATION AND EXPERIMENTAL STUDY ON HYBRID BIT WITH DIFFERENT CUTTERS
}

\author{
Yu, J. P.*; Zou, D. Y.*; Liu, X. A.* \& Zhang, Y.** \\ ${ }^{*}$ School of Petroleum Engineering, China University of Petroleum (East China), Qingdao, 266580, \\ China \\ ${ }^{* * *}$ Department of Petroleum Engineering, University of Alaska Fairbanks, Fairbanks, Alaska, 99775, \\ United States of America \\ E-Mail: eugene_yujp@126.com,upc_zoudy@163.com,b14020055@s.upc.edu.cn, \\ yzhang35@alaska.edu
}

\begin{abstract}
Rate of penetration $(R O P)$ and wear resistance are important evaluation indexes for the performance of bits. This study proposed a novel bit design method using diamond impregnated block (DIB) and polycrystalline diamond compact (PDC) cutter by simulation experiment analysis to enhance the ROP and service life of PDC bits in hard formation. A DIB material suitable for hard formation was determined by the simulation experiment. A DIB-PDC hybrid bit rock-breaking test model was established by analysing the rock breaking mechanism of DIB-PDC elements. Results demonstrate that the $R O P$ and wear rate of DIB materials are directly proportional to diamond particle size. The ROP of PDC bit is negatively correlated with wear height. The ROP of PDC bit is proportional to weight-on-bit $(W O B)$. The ROP of DIB bits is relatively stable despite the linear correlation with WOB. The ROP of DIB-PDC bits is $1.99 \mathrm{~m} / \mathrm{h}$, which is higher than that of DIB and PDC bits. The result is verified by drilling simulation. The findings provide a good reference for designing personalized PDC bits suitable for special stratum.

(Received in October 2020, accepted in December 2020. This paper was with the authors 1 month for 1 revision.)
\end{abstract}

Key Words: PDC, DIB, Rate of Penetration, Experiment, Simulation

\section{INTRODUCTION}

Owing to its high rock breaking efficiency and long service life, polycrystalline diamond compact (PDC) bit has been extensively used in the field of oil drilling and plays an important role in global oil and gas drilling [1]. According to different formation characteristics and drilling requirements, experts from various countries, such as China, the United States, and Britain, have developed PDC bits with special characteristics by optimizing the arrangement and structure parameters of cutters.

However, with the increasing exploration and development of oil and gas, the shallow and easy-to-develop oil and gas resources are decreasing. Seeking oil and gas resources in deep strata and complex geological environments is an important task in land and sea exploration and development. Formations with strong abrasiveness, high hardness, and poor drillability, such as quartz sandstone, siliceous dolomite, and igneous rock, are found in the drilling of deep and ultra-deep wells. However, the existing drilling tools and methods for formations with strong abrasiveness have the disadvantages of slow rate of penetration $(R O P)$, short service life of bits, long drilling cycle, and high drilling cost.

Scholars in the field of oil and gas have conducted numerous studies of effectively breaking hard formations and prolonging the service life via reasonable layouts of bit cutters [2-5]. However, in the actual drilling process, the material and layout of cutters and the test model are inapplicable to the formations with strong abrasiveness, high hardness, and poor drillability. Therefore, selecting cutter materials suitable for hard formation, determining the layout of cutters, and developing a bit with high rock breaking efficiency and wear resistance are urgent problems in the drilling field. 
This study selected a novel diamond impregnated block (DIB) using experimental methods based on the analysis of the rock breaking mechanism of DIB-PDC cutting elements, and a rock breaking test of DIB-PDC cutters was conducted on the test bench. A novel hybrid bit integrating DIB and PDC cutter was also designed. The test results of the novel bit were compared with those of DIB and worn PDC bits to provide methodological and theoretical bases for optimizing the design of PDC bits suitable for hard formation.

\section{STATE OF THE ART}

At present, scholars in the fields of oil and gas exploration and bit development and processing have proposed various methods to develop PDC bits suitable for different formations. Niu et al. [6] designed a hybrid disc-shaped bit with high $R O P$ and long service life for the hard formation and had the advantages of conventional PDC and disc-shaped roller bits. The key component of the bit is a disc-shaped insert. Although the bit was studied using an experimental method, they did not consider the performance of the disc-shaped insert. Yu et al. [7] designed a DIBPDC bit suitable for hard stratum with strong abrasiveness and conducted a field test in a fault block. The drilling cost was decreased, but the specific study process and the laboratory test results of the bit cutter materials were not introduced. Miyazaki et al. [8] studied the relationship between rock breaking efficiency and wear resistance of PDC bits in special stratum rocks and parameters via experiments and proposed to select PDC bits based on stratum parameters. Their method can improve the adaptability of PDC bits in special stratum but cannot substantially enhance rock breaking efficiency. Kamatov [9] reported that the existing bits (i.e., roller or PDC bit) cannot achieve satisfactory drilling results because of deep shale, siltstone, limestone, and dolomite with frequent interbedding. Based on engineering tests, he used a roller-PDC bit for complex formation. Garcia et al. [10] proposed to develop hybrid bit technology and argued that combining PDC with cutting elements, such as diamond, can meet the requirements of drilling rock with high compressive strength, good wear resistance, and poor drillability. Agawani et al. [11] combined special PDC cutters with rollers and designed a multifunctional drill bit, which has excellent impact resistance and is suitable for drilling heterogeneous carbonate strata. Moreover, these cutters have higher ROP compared with conventional drill bits. However, their study did not introduce the design method. Mazen et al. [12] studied the influence of bit structure and rock properties on the wear resistance of PDC bits and established a mathematical model for predicting the wear resistance of PDC bits. Drilling parameters were also combined with bit wear problems. They focused on bit wear rather than bit design. Abbas and Musa [13] discussed the engineering requirements of personalized PDC bit in a complex stratum structure and conducted infrared spectrum analysis of wear resistance. However, the design of a personalized bit was not considered. Considering the serious wear of PDC bit in hard and multilayered strata of coal mines, Sun et al. [14] designed a novel PDC bit via simulation and conducted a field test. The bit had high rock breaking efficiency but the wear was still serious. Huang et al. [15] developed a modular rotary PDC bit and investigated the variation law of cutting load and MSE of cutting module under different structural parameters. However, the rotary module of the PDC bit was unstable, and the service life was short. Wang et al. [16] established a three-dimensional dynamic model of bit rock breaking by measuring the mechanical properties of rock and analysed the rock breaking law; however, they failed to propose a bit design method of integrating multiple cutting elements. Saksala et al. [17] simulated rock breaking on a bit-rock coupling model and illustrated the relationship between impact velocity and rock breaking efficiency by combining numerical simulation and experimental study; however, the combination of bit cutting elements was not discussed. Dykstra et al. [18] selected a hybrid PDC-TCI bits and developed a simple model linking drilling parameters and $R O P$ to establish expected weights on bit $(W O B)$ and rotary speeds for 
optimal bit performance. Wang et al. [19] proposed the optimal cutter layout mode of PDC bit for granite and hard sandstone formation by performing laboratory experiments, studied the influence of cutter layout mode on service life and $R O P$, and proposed the design method of personalized bit cutter structure. However, an experimental basis was not given.

The above studies proposed new viewpoints on the integration of cutting elements of PDC bits, analysed personalized bit in the hard stratum, and explored the improvement of the wear resistance of bits. Moreover, personalized bit was designed by integrating cutting elements. However, a few studies selected cutter materials by conducting experiments or designed bits based on experimental data. This study proposed a new method of designing a bit by combining DIBs and PDC cutters through experimental analysis. The interactive rock breaking mechanism of DIB-PDC elements was analysed. A DIB design and test model and a rock breaking test model of DIB-PDC bit were also established. Moreover, the experimental data of DIB were analysed. The results provide a basis for designing DIB-PDC bits suitable for hard stratum.

The remainder of this study is organized as follows. Section 3 analyses the rock breaking mechanism of DIB-PDC elements, establishes the DIB material formula design and test model, determines the rock breaking test model and Drilling model of hybrid bit of DIB-PDC bit. Section 4 examines the test results of DIB material performance and compares DIB-PDC of the $R O P$ of different bits. Furthermore, the rock breaking efficiency of DIB-PDC hybrid bit is verified. Finally, section 5 summarizes the study and concludes the paper.

\section{METHODOLOGY}

\subsection{Interactive rock breaking mechanism of DIB and PDC elements}

PDC bit breaks rock using the PDC cutters installed on the drill bit. The rock breaking mechanical models of non-worn and worn PDC cutters are shown in Fig. 1.

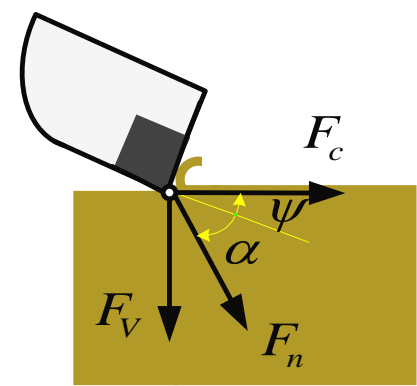

a)

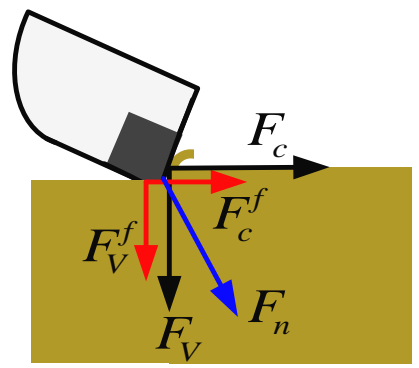

b)

Figure 1: Rock breaking mechanical models of PDC cutters.

When PDC cutters are not worn or slightly worn, the cutting edge is sharp, and the contact area is small. Under the joint action of positive pressure and cutting force, the PDC cutting edge can easily drill and continuously cut rock with large cutting depth and high rock breaking efficiency as shown in Fig. 1 a. When PDC cutters are worn to a certain extent, and a large wear surface parallel to the rock surface is formed, the contact area between the cutting edge and the rock increases. Under the same drilling stress, drilling into the rock becomes difficult, the cutting depth becomes small, and the drilling speed decreases, as shown in Fig. $1 \mathrm{~b}$.

Serious abrasive wear, impact fracture, and thermal damage of PDC cutters are observed when PDC bit drills into hard gravel, and the cutting edge is worn rapidly, thereby forming large wear surfaces. Therefore, PDC bits have poor applicability in abrasive hard strata. After analysing DIB materials, the interactive cutting edge structure of DIB-PDC element is used in accordance with the wear resistance characteristics of DIB materials to realize grinding-cutting interactive rock breaking, thereby improving rock breaking efficiency and wear resistance as 
shown in Fig. 2. The interactive rock breaking mechanism of the DIB-PDC element is as follows.

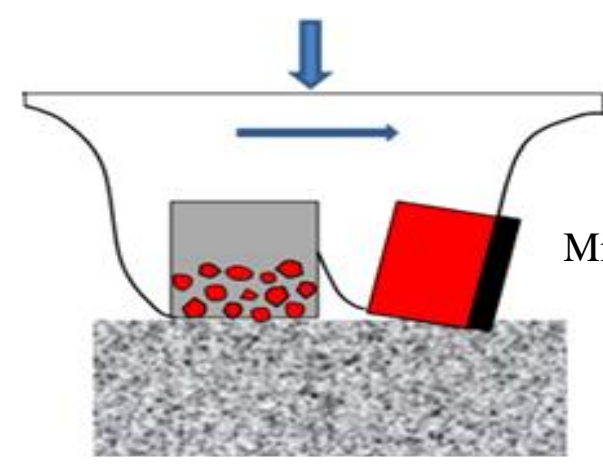

a) DIB controls drilling depth

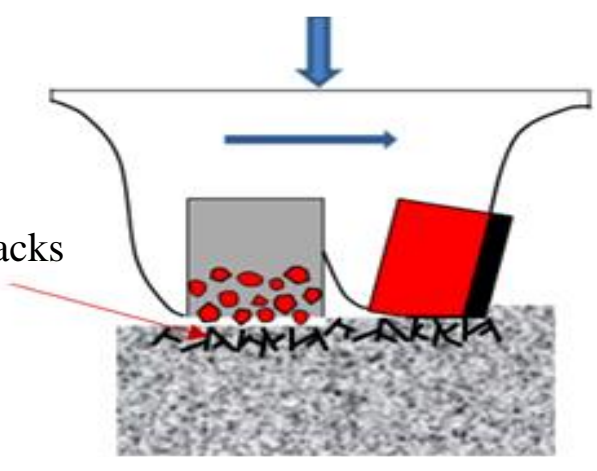

b) grinding-cutting interactive rock breaking

Figure 2: Schematic of interactive rock breaking mechanism of DIB-PDC elements.

The edge of the PDC cutter is sharp at the initial stage of rock breaking. DIBs with certain exposure height differences control the drilling depth to prevent impact damage under large impact load caused by excessive instantaneous drilling depth. Meanwhile, diamond particles are exposed during the friction between DIBs and rock. Drilling into rock becomes difficult when PDC cutters are worn to a certain degree; DIBs bear WOB, and the exposed diamond particles are fine. The bit can also drill into rocks under a small weight. The rock at the well bottom is plowed under the rotating torque, thus forming grooves. Under the extrusion of diamond particles, microcracks are formed on the rock near the bottom and both sides of the grooves. The formation of grooves and microcracks changes the stress state of the rock at the well bottom and decreases the breaking strength. Good mechanical conditions are also created for the large-area cutting of PDC cutters, and the rock breaking efficiency is improved.

\subsection{Formula design and test model of DIB}

The analysis results of the comprehensive anti-drilling characteristics of glutenite formation reveal that the average rock abrasiveness is Grade VI, which is medium and high. The variation range of rock abrasiveness is I-IX. According to the characteristics of the target formation, DIB is conducted with repeated matrix formula analysis and experimental comparison based on extensive investigation and analysis. 50\% WC $+15 \% \mathrm{X} 6-600+25 \% \mathrm{CuSn}(\mathrm{X} 6-600$ is a prealloyed powder with main components of $\mathrm{Fe}, \mathrm{Cu}, \mathrm{Co}$, and $\mathrm{Sn}$ ) is selected as the final matrix formula of DIB. The hardness of the matrix HRC is 45.9, which can meet the performance requirements of the target formation. Five DIB material formulas with different diamond sizes are designed in accordance with the matrix formula, and the diamond concentration is $100 \%$. Table I lists the formula parameters of DIB with five different diamond sizes.

Table I: Diamond particle size parameters of DIB material formula.

\begin{tabular}{|c|c|c|c|}
\hline Matrix formula & $\begin{array}{c}\text { Hardness of } \\
\text { matrix (HRC) }\end{array}$ & $\begin{array}{c}\text { Diamond particle } \\
\text { size }(\mu \mathrm{m})\end{array}$ & $\begin{array}{c}\text { Diamond } \\
\text { concentration }(\%)\end{array}$ \\
\hline $50 \% \mathrm{WC}+$ & & 1180 & \\
$15 \% \mathrm{X} 6-600+$ & 45.9 & 850 & 100 \\
$25 \% \mathrm{CuSn}$ & & 600 & \\
& & 425 & \\
\hline
\end{tabular}

The parameters in Table I reveal that the RJY2000 sintering machine is employed to sinter DIB materials with the hot pressing method (Fig. 3). The sintering temperature is $905^{\circ} \mathrm{C}$, 
the pressure is $30 \mathrm{MPa}$, and the holding time is $5 \mathrm{~min}$. The size of the DIB material is $\Phi 16 \times 10 \mathrm{~mm}$, as shown in Fig. 4 a.

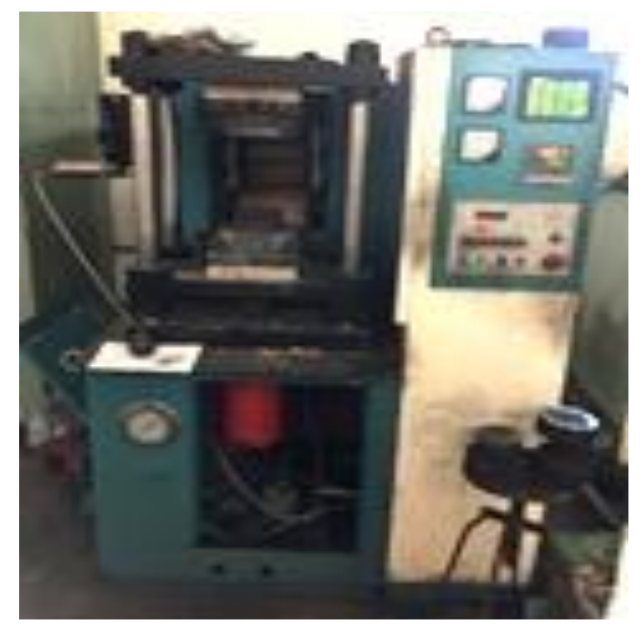

Figure 3: RJY 2000 sintering machine.

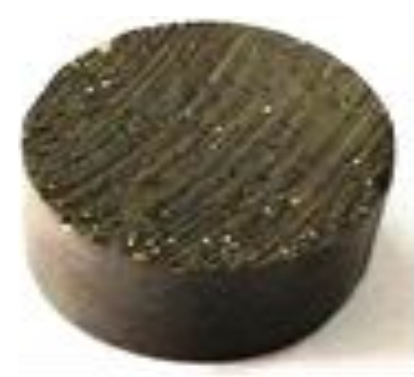

a) $\Phi 16 \times 10 \mathrm{~mm} \mathrm{DIB}$

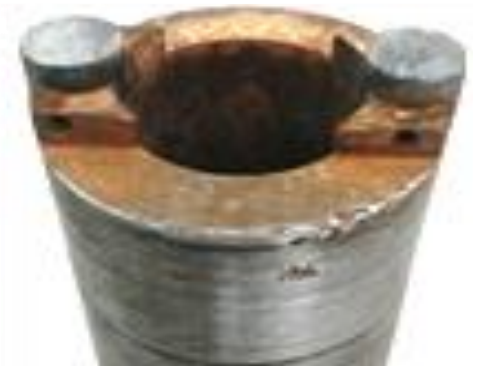

b) coring bit

Figure 4: DIB experimental bit model.

Two sintered DIB materials were symmetrically embedded on the bit, and a two-cutter DIB miniature coring bit model (Fig. 4 b) was processed. The rock breaking efficiency and the wear resistance for siltstone were tested using modified drilling and milling machines. The siltstone with the drillability grade value of 7.8 is selected as the experimental rock sample. The WOB is $3.0 \mathrm{kN}$, and the rotation speed is $198 \mathrm{rpm}$. The drilling depth of the bit is $10 \mathrm{~cm}$ due to the size limitation of the experimental rock sample. The sample is drilled three times in every experiment, and the average value is taken as the real experimental data.

The $R O P$ and wear rate of bit cutters are performance evaluation indexes in the field of oil and gas exploration. The wear rate of the cutters is calculated as follows:

$$
\text { wear } \text { rate }=\frac{a_{1}-a_{2}}{s},
$$

where $a_{1}$ is the initial mass of DIB, $a_{2}$ is the mass of worn DIB, and $s$ is the total footage of DIB.

\subsection{Simulation experiment model of hybrid bit}

According to the experimental purpose, PDC and DIB bits are designed and processed as shown in Fig. 5. The diameter of the experimental bits is $77 \mathrm{~mm}$. Six $\Phi 16 \times 10 \mathrm{~mm}$ PDC cutters and DIBs are installed. The rotation speed of the bit is $50 \mathrm{rpm}$, and the siltstone with a drillability grade of 7.8 is the experimental rock sample. 


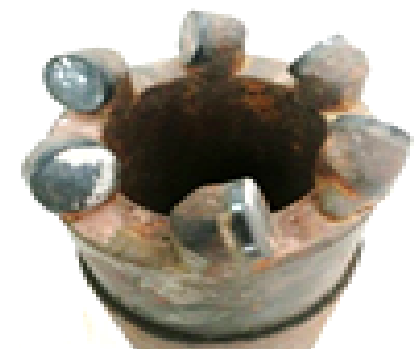

a) PDC bit

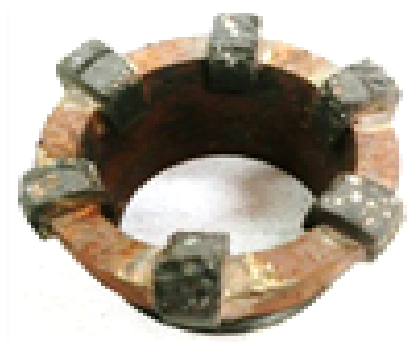

b) DIB bit

Figure 5: Bit models for performance comparison test.

A worn DIB-PDC experimental bit model is designed to verify the rock breaking mechanism and performance of DIB-PDC bits as shown in Fig. 6. The outer diameter of the bit is $77 \mathrm{~mm}$. Three $\Phi 16 \times 10 \mathrm{~mm}$ PDC cutters (three cutters with a single colour in Fig. 6 a) and three $\Phi 16 \times 10 \mathrm{~mm}$ DIBs (three blocks with two colours in Fig. 6 a) are installed on the bit. The DIB-PDC rock breaking experiment is completed on an XY-2B bit test bench. The target rock is siltstone with a drillability grade of 7.8 .

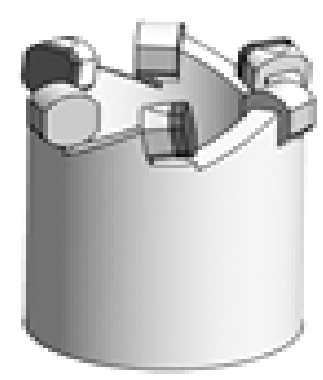

a)

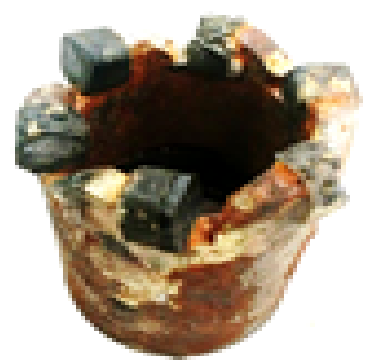

b)

Figure 6: DIB-PDC combined experimental bit model.

\subsection{Drilling model of PDC and hybrid bit}

According to section 3.3, drilling models of PDC and hybrid bits are established as shown in Fig. $7 \mathrm{a}$ and the grid division as in Fig. 7 b. According to relevant data [20-23] and Saint-Venant principle, the radial dimension of the rock calculated by the simulation should be more than three times that of the bit to meet the accuracy analysis requirement. A $\Phi 600 \mathrm{~mm} \times 200 \mathrm{~mm}$ cylindrical rock model was established. The material model proposed by Holmquist, Johnson and Cook (HJC) were used to simulate rock breaking during drilling [24]. The drilling speed was $0.0005 \mathrm{~m} / \mathrm{s}$ and rotational speed loads was $6 \mathrm{rad} / \mathrm{s}$. LS-PREPOST, a special post-processor for the LS-DYNA software, was employed to obtain the data of the force change for drilling simulation.

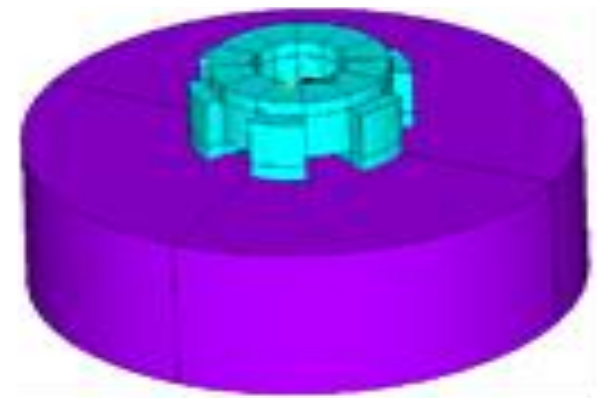

a)

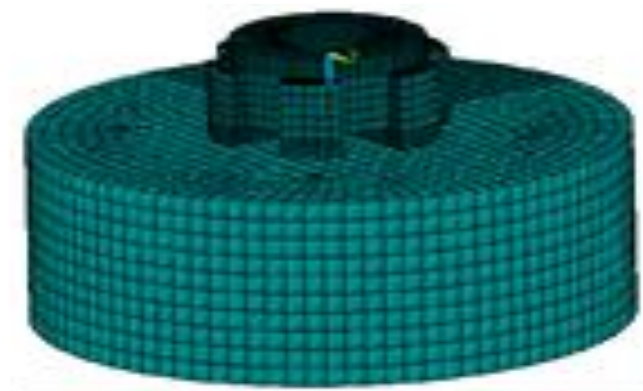

b)

Figure 7: Drilling model and grid division. 


\section{RESULTS ANALYSIS AND DISCUSSION}

\subsection{Analysis of experimental results of DIB material performance}

The rock breaking efficiency and the wear resistance of DIB were tested on the experimental bench. The drillability grade of the siltstone is 7.8 , and the rock morphology after the rock breaking test is presented in Fig. 8. DIB performance test results are given in Table II.

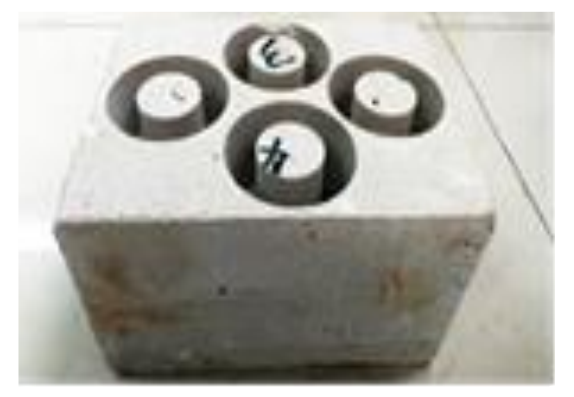

Figure 8: Rock fracture morphology in DIB material performance experiment.

Table II: DIB performance test results.

\begin{tabular}{|c|c|c|c|c|}
\hline $\begin{array}{c}\text { Serial } \\
\text { number }\end{array}$ & $\begin{array}{c}\text { Diamond } \\
\text { particle size } \\
(\mu \mathrm{m})\end{array}$ & ROP $(\mathrm{m} / \mathrm{h})$ & $\begin{array}{c}\text { Wear rate } \\
(\mathrm{g} / 100 \mathrm{~m})\end{array}$ & $\begin{array}{c}\text { Times of } \\
\text { repetition }\end{array}$ \\
\hline 1 & 1180 & 1.44 & 4.34 & 3 \\
2 & 850 & 1.02 & 2.68 & 3 \\
3 & 600 & 1.01 & 2.53 & 3 \\
4 & 425 & 0.87 & 2.45 & 3 \\
5 & 250 & 0.54 & 1.54 & 3 \\
\hline
\end{tabular}

Fig. 9 describes the relationship between the rock breaking efficiency of DIB material and diamond particle size. The rock breaking efficiency of DIB material increases with the diamond particle size. Fig. 10 presents the relationship between the wear rate of DIB material and diamond particle size, which indicates that the wear rate of DIB material decreases with the diamond particle size. Material 1 should be selected on the basis of the analysis in Fig. 9. The rock breaking efficiency of Materials 2 and 3 is similar. Fig. 10 shows that Material 1 has a high wear rate, which is not conducive to the service life of the bit. Material 5 has a low wear rate, but its rock breaking efficiency is poor. The grinding rates of Materials 2, 3, and 4 are consistent and relatively stable. Considering rock breaking efficiency and wear resistance, Material 3 in Table I is recommended, that is, a diamond particle size of $600 \mu \mathrm{m}$.

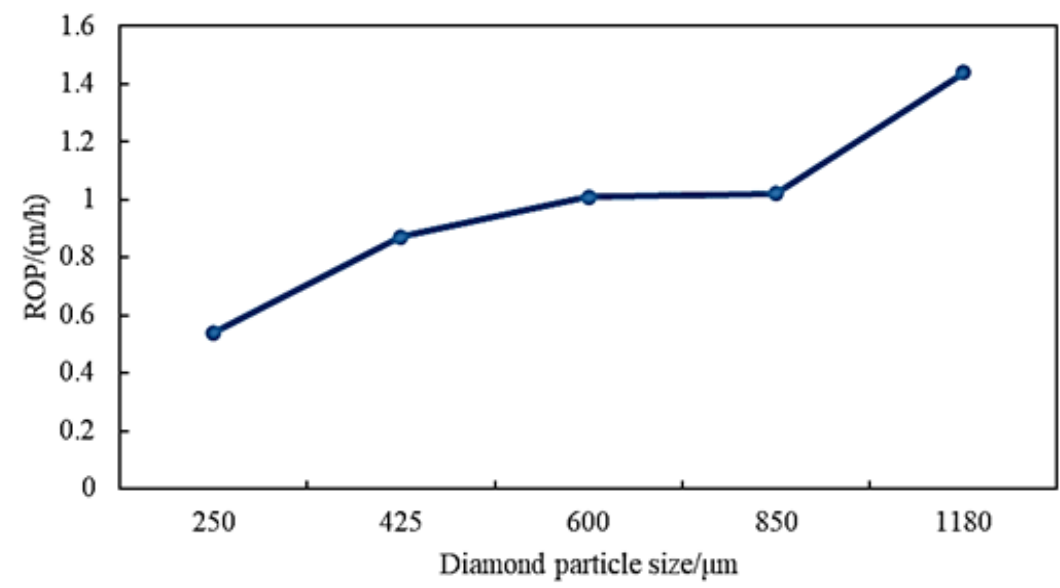

Figure 9: Relationship between rock breaking efficiency of DIB material and diamond particle size. 


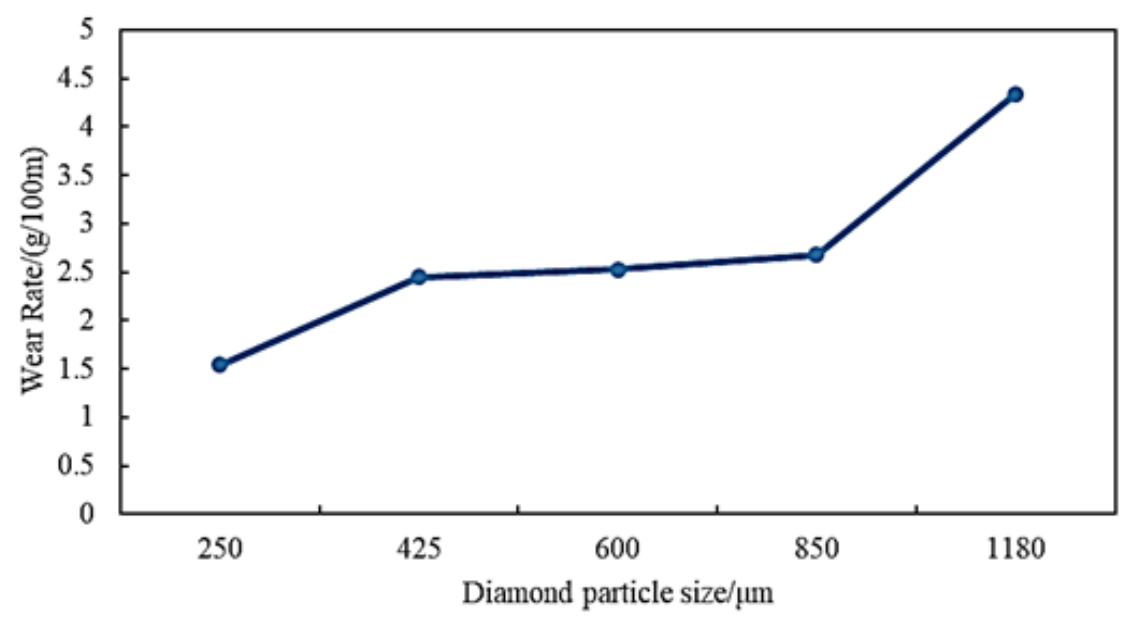

Figure 10: Relationship between wear rate of DIB material and diamond particle size.

\subsection{Experimental result analysis of rock breaking efficiency of PDC and DIB bits}

Rock breaking experiments of PDC and DIB bits were conducted on an XY-2B bit test bench in a laboratory. The rotation speed is $50 \mathrm{rpm}$, and the drillability grade of siltstone is 7.8 . Table III presents the rock breaking efficiency of PDC and DIBs bit under different WOBs.

Table III: Experimental results of rock breaking efficiency of PDC and DIB bits.

\begin{tabular}{|c|c|c|c|c|c|c|}
\hline \multirow{2}{*}{$\begin{array}{c}\text { Type of } \\
\text { bit }\end{array}$} & $\begin{array}{c}\text { Cutter wear } \\
\text { height } \\
(\mathrm{mm})\end{array}$ & \multicolumn{5}{|c|}{ WOB $(\mathrm{kN})$} \\
\cline { 3 - 7 } & 0 & 4 & 8 & 10 & 12 & 15 \\
\hline \multirow{4}{*}{ PDC bit } & 0.22 & 2.18 & 3.01 & 3.65 & 4.12 \\
& 0.5 & 0.95 & 1.79 & 2.41 & 2.99 & 3.61 \\
& 1.0 & 0.71 & 1.08 & 1.33 & 1.60 & 2.15 \\
& 1.5 & 0.47 & 0.81 & 1.02 & 1.21 & 1.43 \\
& 2.0 & 0.40 & 0.68 & 0.84 & 0.94 & 1.11 \\
& 2.5 & 0.28 & 0.43 & 0.51 & 0.59 & 0.75 \\
\hline DIB bit & 0 & 1.25 & 1.30 & 1.38 & 1.49 & 1.52 \\
\hline
\end{tabular}

Fig. 11 describes the variation trend of the rock breaking efficiency of PDC bit with PDC wear height. A large wear height leads to a low rock breaking efficiency. The service life of PDC bits is short despite its high rock breaking efficiency. The rock breaking efficiency decreases when the PDC bit is worn, thus reducing the drilling efficiency.

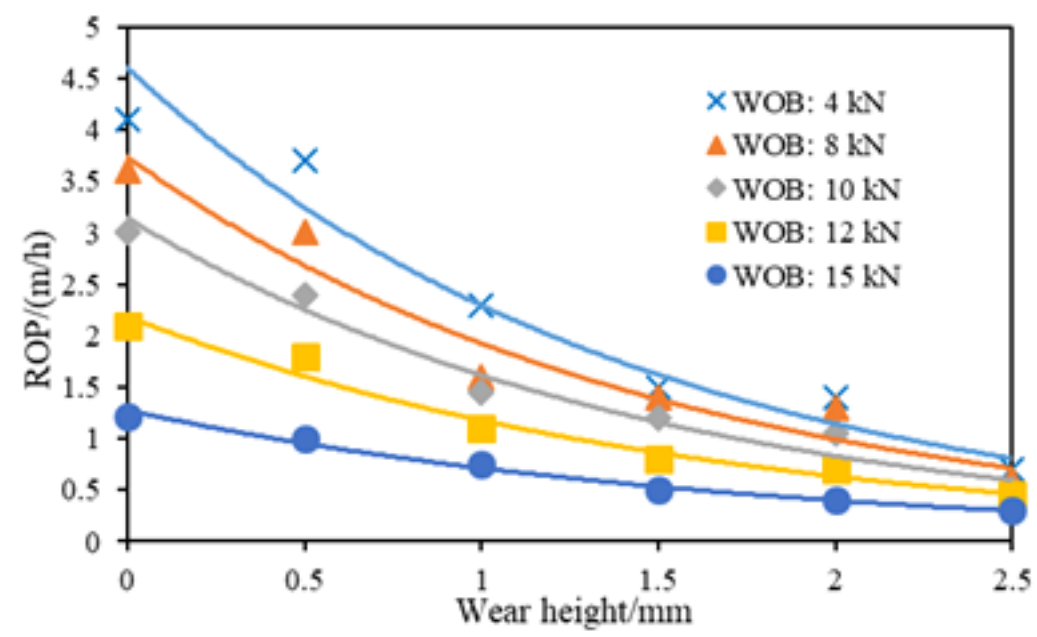

Figure 11: Relationship between rock breaking efficiency of PDC bit and PDC wear height. 
Fig. 12 shows that although the rock breaking efficiency of the PDC bit increases with the $W O B$, such an efficiency substantially decreases with the increase in wear height, which intersects with DIB bit. The rock breaking efficiency is also proportional to $W O B$, but the basic rotation rate is stable, which verifies the rock breaking mechanism of DIB bit. In Fig. 12, although the rock breaking efficiency of PDC bit increases with the WOB and decreases sharply as the wear height increases, which intersects with DIB bit. Although the rock breaking efficiency is also proportional to $W O B$, the basic $R O P$ is stable, and the rock breaking mechanism of DIB bit is verified.

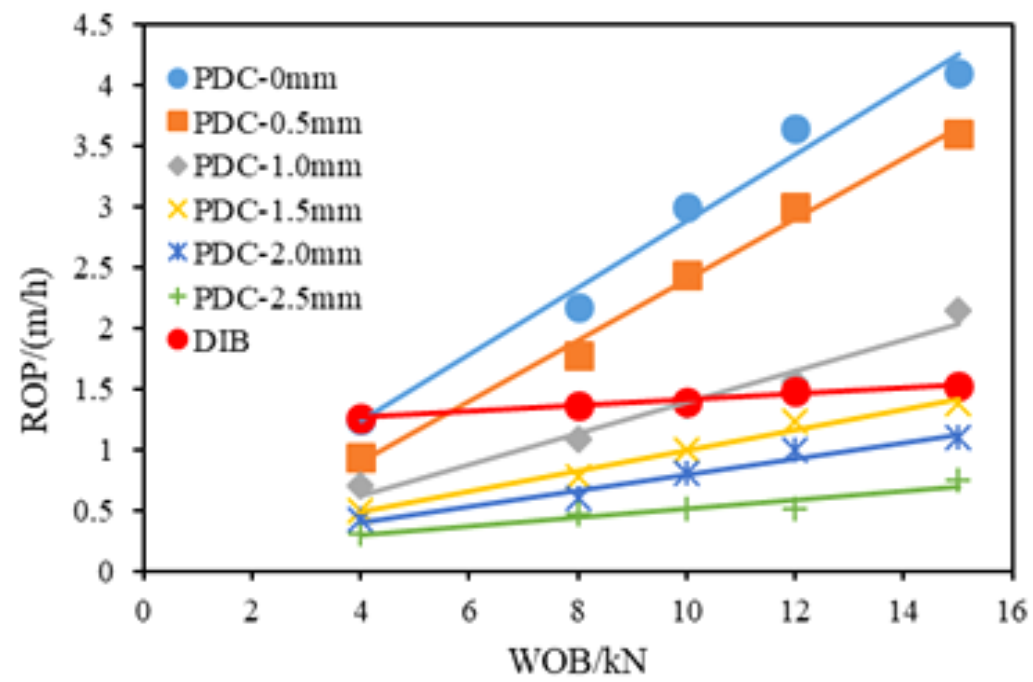

Figure 12: Comparison of rock breaking efficiency of PDC and DIB bits.

\subsection{Analysis of simulation experiment results of hybrid bit}

The analysis of test results in section 4.2 reveals that the rock breaking efficiency of PDC bit when drilling hard rock decreases rapidly with the increase in PDC wear height. Therefore, the low rock breaking efficiency of PDC bit is due to the rapid wear of PDC cutters in gravel hard stratum. When the wear height of PDC cutters is less than $1.0 \mathrm{~mm}$, PDC bit has higher rock breaking efficiency compared with DIB bit. When the wear height of PDC cutters exceeds $1.5 \mathrm{~mm}$, the rock breaking efficiency of PDC bit substantially decreases compared with that of DIB bit. This result indicates that the rock breaking efficiency of PDC bit in hard gravel stratum can be improved as long as the wear height of PDC bit is controlled. The experiment of the worn DIB-PDC bit was performed on an XY-2B bit test bench to verify the wear resistance and rock breaking efficiency of DIB-PDC bit. The wear height of the PDC bit is $1 \mathrm{~mm}$, and the experimental parameters are as follows: $W O B$ is $15 \mathrm{kN}$, and rotation speed is $50 \mathrm{rpm}$. The siltstone has a drillability grade of 7.8. The experimental results are given in Table IV. The rock breaking efficiency of DIB-PDC bits is notably higher than that of DIB and worn PDC bits.

Table IV: Simulation experiment results of hybrid bit.

\begin{tabular}{|c|c|c|c|}
\hline Type of bit & DIB-PDC bit & PDC bit & DIB bit \\
\hline$R O P(\mathrm{~m} / \mathrm{h})$ & 1.99 & 1.43 & 1.52 \\
\hline
\end{tabular}

\subsection{Analysis of simulation results}

Fig. 13 shows the time-varying diagram of the axial force $(W O B)$, PDC tangential force and DIB-PDC tangential force. It can be seen from the Fig. 13 that, under the same WOB, the tangential force of PDC bit and hybrid bit are the same in the initial drilling. As drilling continues, the tangential force of DIB-PDC bit is smaller than that of PDC bit, which indicates 
that DIB-PDC bit is easier to break rock. This result is identical to the rock breaking mechanism of DIB and PDC elements.

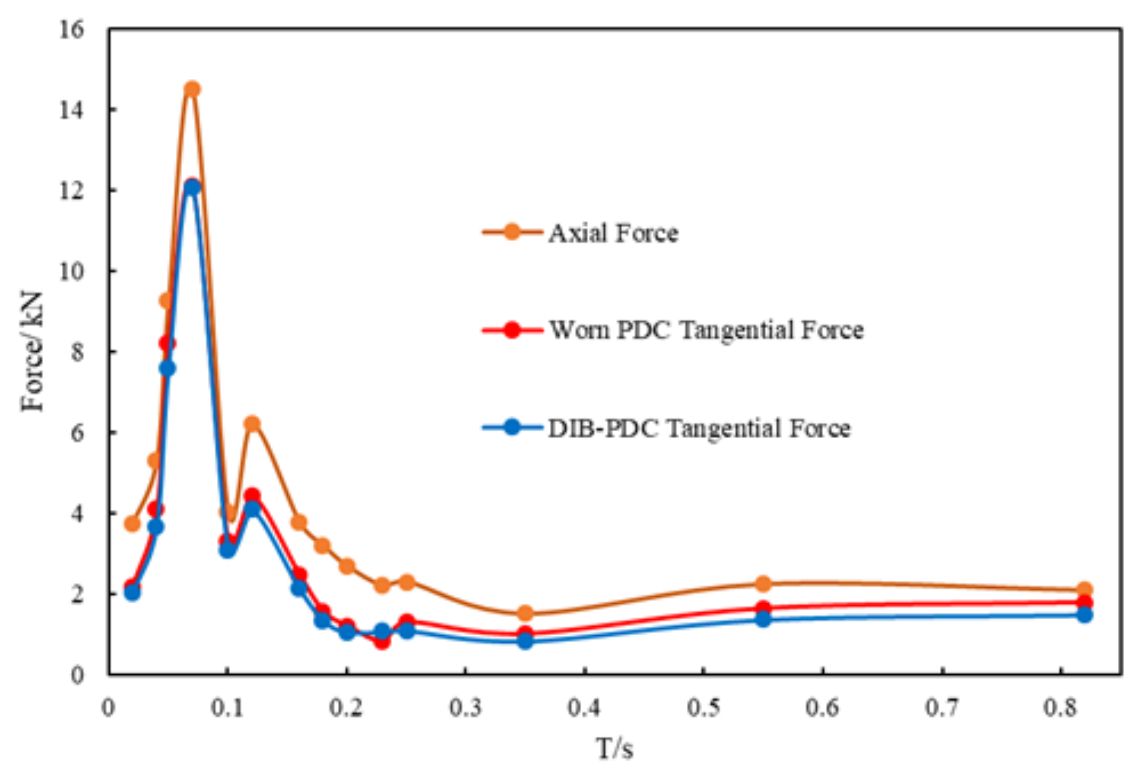

Figure 13: The time-varying diagram of axial and tangential force.

\section{CONCLUSION}

This study proposed a new design method of combining DIB and PDC elements through experimental analysis to improve the rock breaking efficiency and prolong the service life of PDC bits when drilling hard stratum. A DIB material design and test model and a DIB-PDC bit rock-breaking test model were established by analysing the interactive rock breaking mechanism of DIB and PDC elements. The experimental data of DIB materials were analysed, and the DIB material suitable for hard stratum was determined. A novel model integrating DIBPDC elements was designed. Based on the analysis and comparison of the test results, the following conclusions could be drawn.

(1) The rock breaking efficiency and wear rate of DIB materials are positively correlated with diamond particle size.

(2) The rock breaking efficiency of PDC bit is negatively correlated with its wear height. A PDC bit with a small wear height leads to high rock breaking efficiency.

(3) The rock breaking efficiency of PDC bit is proportional to WOB. The rock breaking efficiency of DIB bit has a linear correlation with $W O B$, but its rock breaking efficiency is relatively stable.

(4) The selected DIB material has a wear resistance, and the DIB-PDC bit has a long service life.

(5) The rock breaking efficiency of DIB-PDC bits reaches $1.99 \mathrm{~m} / \mathrm{h}$, which is higher than that of DIB and PDC bits.

The interactive rock breaking mechanism of DIB-PDC elements was analysed in this study. A novel DIB with high rock breaking efficiency and strong wear resistance was designed by conducting tests. A DIB-PDC hybrid bit was designed on the basis of the experimental analysis. By comparing the bit performance, the rock breaking efficiency and the wear resistance of the DIB-PDC bit were proven to be higher than those of the PDC and DIB bits. The proposed bit design method has high reference value for designing special bit structures and improving wear resistance and rock breaking efficiency of bits. The design method was proposed for hard strata (such as glutenite). The universality of this method will be verified by accumulating experimental data in future studies. 
Yu, Zou, Liu, Zhang: Simulation and Experimental Study on Hybrid Bit with Different Cutters

\section{ACKNOWLEDGEMENT}

This work was supported by the $13^{\text {th }}$ Five Year Plan of Major National Special Projects of China (Grant No. 2016ZX05003-004-006).

\section{REFERENCES}

[1] Zhang, J. Z. (2013). Study and Practice of Drilling Technology, China University of Mining and Technology Press, Xuzhou (in Chinese)

[2] Ma, Y. C.; Huang, Z. Q.; Li, Q.; Zhou, Y.; Peng, S. J. (2018). Cutter layout optimization for reduction of lateral force on PDC bit using Kriging and particle swarm optimization methods, Journal of Petroleum Science and Engineering, Vol. 163, 359-370, doi:10.1016/ j.petrol.2018.01.001

[3] Huang, K. L.; Ai, Z. J.; Yang, Y. X.; Xie, Z. L. (2019). The improved rock breaking efficiency of an annular-groove PDC bit, Journal of Petroleum Science and Engineering, Vol. 172, 425-435, doi:10.1016/j.petrol.2018.09.079

[4] Boussahaba, H.; Sugumar, J.; Vrnak, K.; Benyoucef, L.; Fadtare, A.; Al-Shammari, A.; AlFailakawi, K.; Dutta, A.; Al-Khaldy, M. (2020). New and advanced PDC bit design with innovative backup layout cutters helps extend bit life without sacrificing rate of penetration during a heterogeneous application, Northwest Kuwait, Proceedings of the International Petroleum Technology Conference, Paper IPTC-20030-MS, 684-695, doi:10.2523/IPTC-20030-MS

[5] El-Gayar, M.; Ali, T. S.; Talaf, M. A. (2017). Multilevel force-balanced cutting structure layout helped solve PDC bit dullness issues resulting from geosteering in thin reservoirs, Proceedings of SPE Bergen One Day Seminar 2017, Paper SPE-185934-MS, 587-600, doi:10.2118/185934-MS

[6] Niu, S. W.; Zheng, H. L.; Yang, Y. X.; Chen, L. (2018). Experimental study on the rock-breaking mechanism of disc-like hybrid bit, Journal of Petroleum Science and Engineering, Vol. 161, 541550, doi:10.1016/j.petrol.2017.12.011

[7] Yu, J. P.; Zou, D. Y.; Liu, X. A. (2020). Design and application of novel hybrid drill bit for hard formation with strong abrasivity, Diamond \& Abrasives Engineering, Vol. 40, No. 3, 67-71, doi:10.13394/j.cnki.jgszz.2020.3.0011

[8] Miyazaki, K.; Ohno, T.; Karasawa, H.; Imaizumi, H. (2019). Performance of polycrystalline diamond compact bit based on laboratory tests assuming geothermal well drilling, Geothermics, Vol. 80, 185-194, doi:10.1016/j.geothermics.2019.03.006

[9] Kamatov, K. (2013). Hybrid drill bit for horizontal drilling in highly interbedded formations of Timano-Pechora Arctic fields, Proceedings of SPE Arctic and Extreme Environments Technical Conference and Exhibition, Paper SPE-166841-MS, Vol. 1, 443-466, doi:10.2118/166841-MS

[10] Garcia, A.; Barocio, H.; John, D.; Perez Avila, E. A. (2013). Hybrid bit technology expands application range in harsh rock environments, Proceedings of SPE/IADC Middle East Drilling Technology Conference \& Exhibition, Paper SPE-166766-MS, 672-683, doi:10.2118/166766-MS

[11] Agawani, W.; Al-Enezi, D. R.; Pandya, M.; Gupta, P.; Abdelhamid, A.; Al-Habib, H.; El-Touny, S.; Ahmed, T.; Mohammed, J. A. (2018). Engineered hybrid drill bit technology doubles drilling performance in impact-prone carbonates heavy oil application, Proceedings of SPE International Heavy Oil Conference and Exhibition, Paper SPE-193704-MS, 667-680, doi:10.2118/193704-MS

[12] Mazen, A. Z.; Mujtaba, I. M.; Hassanpour, A.; Rahmanian, N. (2020). Mathematical modelling of performance and wear prediction of PDC drill bits: Impact of bit profile, bit hydraulic, and rock strength, Journal of Petroleum Science and Engineering, Vol. 188, Paper 106849, 18 pages, doi:10.1016/j.petrol.2019.106849

[13] Abbas, R. K.; Musa, K. M. (2019). Using Raman shift and FT-IR spectra as quality indices of oil bit PDC cutters, Petroleum, Vol. 5, No. 3, 329-334, doi:10.1016/j.petlm.2018.10.003

[14] Sun, R. J.; Ju, P.; Shi, Z. J. (2017). Simulation study of new directional drilling PDC bit used in coal mine, Geosystem Engineering, Vol. 20, No. 3, 142-148, doi:10.1080/12269328.2016.1246981

[15] Huang, K. L.; Yang, Y. X.; Liu, Y.; Zhong, Y. P.; Ren, H. T. (2020). Study on rock breaking mechanism of PDC bit with rotating module, Journal of Petroleum Science and Engineering, Vol. 192, Paper 107312, 9 pages, doi:10.1016/j.petrol.2020.107312 
[16] Wang, X.; Liu, Z. Y.; Qu, S. N.; Su, C. (2018). Research on rock breaking simulation of PDC bit under rock property parameters in Weibei Oilfield, China Energy and Environmental Protection, Vol. 40, No. 9, 99-103, doi:10.19389/j.cnki.1003-0506.2018.09.020

[17] Saksala, T.; Gomon, D.; Hokka, M.; Kuokkala, V.-T. (2014). Numerical and experimental study of percussive drilling with a triple-button bit on Kuru granite, International Journal of Impact Engineering, Vol. 72, 56-66, doi:10.1016/j.ijimpeng.2014.05.006

[18] Dykstra, M. W.; Armenta, M. A.; Mathew Ain, F. A.; Adesokan, O.; Schornick, T. L.; Roy Chowdhury, A.; Allain, M. D. (2018). Converting power to performance: Gulf of Mexico examples of an optimization workflow for bit selection, drilling system design and operation, Proceedings of Offshore Technology Conference (OTC 2018), Paper OTC-29065-MS, Vol. 3, 1906-1934, doi:10.4043/29065-MS

[19] Wang, B.; Li, J.; Zou, D. Y.; Yang, H. W.; Wang, K. (2018). Design and application of a PDC hybrid drill bit with impregnated diamond insert for the hard formation with strong abrasivity, Special Oil \& Gas Reservoirs, Vol. 25, No. 1, 169-174, doi:10.3969/j.issn.1006-6535.2018.01.035

[20] Wan, Q.; Zheng, M. L.; Yang, S. C.; Sun, J. K. (2019). Optimization of micro-texture distribution through finite-element simulation, International Journal of Simulation Modelling, Vol. 18, No. 3, 543-554, doi:10.2507/IJSIMM18(3)CO15

[21] Artola, L. G.; Arriola, P. J. A.; de Buruaga, M. S.; Soler, D.; de Zarate, G. O.; Aizpuru, O.; Mielgo, R. (2019). Finite element modelling of the turning of quenched steels, DYNA, Vol. 94, No. 3, 331337, doi: $10.6036 / 8846$

[22] Poklemba, R.; Duplakova, D.; Zajac, J.; Duplak, J.; Simkulet, V.; Goldyniak, D. (2020). Design and investigation of machine tool bed based on polymer concrete mixture, International Journal of Simulation Modelling, Vol. 19, No. 2, 291-302, doi:10.2507/IJSIMM19-2-518

[23] Ahmadi, M.; Seyedin, S. H.; Seyedin, S. V. (2019). Investigation of the mechanical performance of fiber-modified ceramic composites using finite element method, Tehnicki glasnik-Technical Journal, Vol. 13, No. 3, 173-179, doi:10.31803/tg-20181006143504

[24] Zhang, S. R.; Song, R.; Wang, C.; Shang, C.; Wei, P. Y. (2019). Modification of a dynamic constitutive model - HJC model for roller-compacted concrete and numerical verification, Journal of Vibration and Shock, Vol. 38, No. 12, 25-31, doi:10.13465/j.cnki.jvs.2019.12.004 